\title{
Five Decades of Marine Megafauna Surveys from Micronesia
}

\author{
Summer L. Martin ${ }^{1,2 *}$, Kyle S. Van Houtan ${ }^{3,4}$, T. Todd Jones ${ }^{2}$, Celestino F. Aguon ${ }^{5}$, \\ Jay T. Gutierrez ${ }^{5}$, R. Brent Tibbatts ${ }^{5}$, Shawn B. Wusstig ${ }^{5}$ and Jamie D. Bass ${ }^{5}$ \\ ${ }^{1}$ National Research Council, National Academy of Sciences, Washington, DC, USA, ${ }^{2}$ Marine Turtle Biology and Assessment \\ Program, Pacific Islands Fisheries Science Center, NOAA Fisheries, Honolulu, HI, USA, ${ }^{3}$ Director's Office, Pacific Islands \\ Fisheries Science Center, NOAA Fisheries, Honolulu, HI, USA, ${ }^{4}$ Nicholas School of the Environment, Duke University, \\ Durham, NC, USA, ${ }^{5}$ Division of Aquatic and Wildlife Resources, Guam Department of Agriculture, Mangilao, Guam
}

\section{OPEN ACCESS}

Edited by:

Loren McClenachan, Colby College, USA

Reviewed by: Laura J. May-Collado, University of Vermont, USA Joshua Adam Drew, Columbia University, USA

${ }^{*}$ Correspondence: Summer L. Martin summer.martin@noaa.gov

Specialty section: This article was submitted to Marine Conservation and Sustainability

a section of the journal Frontiers in Marine Science

Received: 09 October 2015 Accepted: 11 December 2015 Published: 11 January 2016

Citation: Martin SL, Van Houtan KS, Jones TT, Aguon CF, Gutierrez JT, Tibbatts RB, Wusstig SB and Bass JD (2016) Five Decades of Marine Megafauna

Surveys from Micronesia.

Front. Mar. Sci. 2:116. doi: 10.3389/fmars.2015.00116
Long-term data are critical for assessing the status, trends, abundance, and distributions of wildlife populations. However, such data streams are often lacking for protected species, especially highly mobile marine vertebrates. Using five decades of aerial surveys, we assessed changes in marine megafauna on the insular coral reef ecosystem of Guam (Marianas Archipelago in Micronesia). The data allowed estimates of relative abundance, trends, and geographic distributions for several important taxa: sea turtles, sharks, manta rays, small delphinids, and large delphinids. These surveys occurred in 32 years from 1963 to 2012 amounting to 632 flights lasting $809 \mathrm{~h}$ over a $70.16 \mathrm{~km}^{2}$ area. Over this span, surveyors recorded 10,622 turtle, 1026 shark, 60 manta ray, 7515 small delphinid, and 95 large delphinid observations. Since the 1960s, sea turtles increased an order of magnitude $(r=0.07)$ and sharks decreased 5 -fold $(r=-0.03)$. Turtle increases were largely restricted to one geographic area, where optimal habitat coincides with low human density and a marine protected area. Shark observations declined proximate to human population centers. Trends for the other taxa were less informative, but each taxon had geographic foci. Protections in the region may be working to recover turtle populations, but failing (or have not yet had sufficient time) to recover overfished shark populations. Long-term analyses of vulnerable marine megafauna in this data-limited region are uncommon, and should be used to guide more focused studies that inform regional management and conservation of these species.

Keywords: coral reef ecosystems, long-term monitoring, marine protected areas (MPA), Marianas archipelago, Guam, reef sharks, sea turtles

\section{INTRODUCTION}

Long-term data are important for assessing the conservation status of populations, but they are lacking for many marine species, particularly large vertebrates (Pimm, 1991; Brown et al., 2001; Willis and Birks, 2006; Magurran et al., 2010). In the recent green turtle (Chelonia mydas) status review under the U.S. Endangered Species Act, for example, only 32 of 462 (7\%) global nesting sites had sufficient data to analyze abundance trends (Seminoff et al., 2015). Similarly, for sharks, although declines have been documented for pelagic species (Baum et al., 2003; Myers and Worm, 2003; Baum and Myers, 2004; Dulvy et al., 2008), the status of populations in reef ecosystems is poorly understood (Ward-Paige et al., 2010). For cetaceans, 45 of 87 (52\%) species on the IUCN Red List are classified as data deficient (lacking robust data on abundance and distribution) and cannot 
be further assessed (IUCN, 2015), thereby limiting management. The collection of long-term data provides important baselines for understanding population changes due to natural dynamics, anthropogenic impacts, and climate change (Van Houtan and Halley, 2011). Besides assessing status and past trends, such data streams may also allow scientists and managers to evaluate and target recovery potentials of historically over-exploited species (Lotze et al., 2011).

The lack of long-term data may be most apparent in developing nations and small island developing states, where various obstacles have hindered science infrastructure and environmental monitoring. This is particularly the case in the insular Western Pacific (Micronesia, Polynesia, and Melanesia). In this region, the political administration of local areas has been dynamic, with governance shifting in the last century from various European and Asian nations to the U.S., and in many places, to local independence. Sustained financial and technical resources, which are required to establish scientific infrastructure, have been largely unavailable (Ban et al., 2009). The insular Pacific encompasses a large section of the Pacific Ocean, with thousands of remote islands and a multitude of nations and cultures, further exacerbating data collection issues. The species themselves also add complexities. Large marine vertebrates are highly mobile and logistically challenging to study at scales that are appropriate for estimating population abundance and trends. Changing political institutions, limited economic and scientific resources, and vast geographic area have likely inhibited the existence of long-term marine biological data streams in the insular Western Pacific. However, this infrastructure may be important for understanding and addressing the future challenges from climate change, which is likely to affect island resources and nations disproportionately (Nurse et al., 2014).

In the absence of long-term scientific monitoring, historical ecologists often rely on non-traditional information sources (e.g., archeological and historical records, photographs, and living memory) to develop proxies and reconstruct past ecosystems (Pandolfi et al., 2003; Sáenz-Arroyo et al., 2005; McClenachan, 2009a,b; Guidetti and Micheli, 2011; Van Houtan et al., 2012, 2013; Kittinger et al., 2013; Van Houtan and Kittinger, 2014). In this study, however, we present a rare opportunity to examine historical trends in megafauna populations using scientific data from reefs at an insular Western Pacific island. We analyze a unique time series containing five decades of systematic aerial survey data from Guam to estimate relative abundances, trends, and geographic distributions of sea turtles, elasmobranchs, and cetaceans. Aerial surveys are an effective tool for estimating inwater population abundance for these taxa (Forney and Barlow, 1998; Kessel et al., 2013; Seminoff et al., 2014; Fuentes et al., 2015). Data from early years of these surveys provided insight into local sea turtle abundance (Hensley and Sherwood, 1993; Pritchard, 1995; Wiles et al., 1995), but long-term analysis of this time series currently does not exist for any of the above taxa.

Guam, a U.S. territory, is the southernmost island in the Mariana Archipelago and the largest, most populated island in Micronesia (Porter et al., 2005). Fish, turtles, and other marine resources have been integral components of the culture for thousands of years (Amesbury and Hunter-Anderson, 2003). Both local and U.S. laws, including the Endangered Species Act (1973), the Marine Mammal Protection Act (1972), and the Shark Conservation Act (2011), afford protection to marine species on Guam. The species in this study are of conservation concern, yet their status and regional population trends are poorly known. The aerial survey data provide a means to assess the status of these populations after years of protection.

\section{METHODS}

\section{Aerial Surveys}

Guam Department of Agriculture Division of Aquatic and Wildlife Resources (DAWR) has conducted coastal aerial surveys to monitor recreational and commercial fishing since 1963. Aerial surveys complement creel (land-based fisher) surveys, which combine interviews and observations to quantify fishing effort and catch. Combined, the aerial and creel surveys allow DAWR to monitor inshore fishing activities across a variety of gears (e.g., spears, nets, and hook-and-line, each employed with and without boat support). Aerial surveys occurred during three time periods: 1963-1965, 1975-1979, and 1989-2012. Weather permitting (i.e., no typhoons approaching and wind speed less than 20 knots), aerial surveys were conducted semimonthly (24 surveys per year under ideal conditions).

Aerial survey methods remained relatively consistent over the entire period of data collection with the exception that early surveys (1963-1965) used helicopters (e.g., Sikorsky, SH3 Sea King), and later surveys (1975-2012) used 4-seat singleengine fixed-wing airplanes (e.g., Cessna, 172 Skyhawk). Prior to 1989 , the island was divided into 12 arbitrary fishing zones (Supplementary Figure S1) for creel and aerial survey purposes. From 1989 on, the 12 zones were further subdivided into a 92-zone system (Supplementary Figure S1) to capture more detailed information on fishing activities. Each survey began in the same location (Supplementary Figure S1, zone 11 in the 92zone system) and circumnavigated the entire island clockwise once. The survey path included a pass into Cocos Lagoon and Apra Harbor, the latter not being surveyed from 1975 to 1979 due to military restrictions. Planes flew at a height of 170-200 $\mathrm{m}$, approximately 200-300 m seaward of the outer reef margin. Helicopters likely flew lower (92 m altitude required for rotarywing aircraft vs. $153 \mathrm{~m}$ for fixed-wing) and may have traveled further offshore based on occasional records of offshore boat activity; documentation of survey methodologies used prior to 1989 is less detailed. In both types of aircraft, a single aerial observer looked landward through a side window, enabling a complete view of the shallow fore and back reef. There were different observers over time, but most flights were covered by two alternating observers in the most recent 20 years. Surveys began in the morning between 0800 and $1200 \mathrm{~h}$, with each survey starting $1 \mathrm{~h}$ later than the previous until reaching $1200 \mathrm{~h}$. Average flight duration was $1.3 \mathrm{~h}(\mathrm{SD}=0.2$, range $=0.4-2.4)$.

In addition to recording fishing activity, observers documented sea turtles, elasmobranchs, and cetaceans seen at the upper ocean surface. Sea turtles included both green 
(Chelonia mydas) and hawksbill turtles (Eretmochelys imbricata), with green turtles generally recognized as the more common species around Guam (Pritchard, 1995; Wiles et al., 1995). Elasmobranchs were separated into reef sharks and reef manta rays (Manta alfredi). Reef sharks most likely included gray (Carcharhinus amblyrhynchos), whitetip (Triaenodon obesus), and blacktip (C. melanopterus) reef sharks, and tawny nurse sharks (Nebrius ferrugineus). Those species comprised 51, 38, 3 , and $8 \%$, respectively, of 600 shark observations from 371 towed-diver surveys in the Marianas (Nadon et al., 2012). Cetaceans were divided into small and large delphinids. Small delphinids included spinner dolphins (Stenella longirostris), and possibly also bottlenose (Tursiops truncatus), pantropical spotted (Stenella attenuata), and rough-toothed dolphins (Steno bredanensis), as well as pygmy killer (Feresa attenuata) and melon-headed whales (Peponocephala electra). Spinner dolphins were the most frequently observed cetacean in recent nearshore small-boat surveys around Guam (Hill et al., 2014). Bottlenose dolphins and pygmy killer whales were also encountered close to the reef environment, but pantropical spotted dolphins and melon-headed whales were typically observed several $\mathrm{km}$ offshore (Hill et al., 2014). Rough-toothed dolphins were only observed close to shore elsewhere in the archipelago (Hill et al., 2014). We believe most of the small delphinids observed on the aerial surveys were spinner dolphins based on their habitat preference and consistent presence around Guam, but occasional sightings of the other species may be included in this group. Large delphinids primarily included short-finned pilot whales (Globicephala macrorhynchus), but possibly also false killer whales (Pseudorca crassidens), pygmy killer whales, and melon-headed whales. While the latter two species are much smaller than the former, they have similar features (e.g., round head, dark color) and could potentially be misidentified from altitude. Distinguishing among the four species can be difficult from a moving aircraft, though animal size, group size, and distance from shore can aid in species identification. Pilot whales, false killer whales, and pygmy killer whales have been observed within $1 \mathrm{~km}$ of shore, with median group sizes of 23, 16, and 8, respectively (Hill et al., 2014). Melon-headed whales were encountered farther from shore (median: $10.8 \mathrm{~km}$ ) and with much larger group sizes (median: 205 individuals) (Hill et al., 2014) than those observed on the aerial surveys (median: 14 individuals). Pilot whales made up the majority (56\%) of sightings of those four species during small-boat surveys around Guam (Hill et al., 2014). Based on both the small-boat and aerial survey observations, we believe that pilot whales made up most, if not all, of the aerial sightings of large delphinids.

Data collection began in 1963 for turtles and sharks, 1978 for small delphinids, and 1989 for manta rays and large delphinids. During surveys, the observer logged the visible number of animals for each taxon into a voice recorder as the aircraft passed over each zone. The species and size of animals were not recorded due to uncertainty associated with collecting those data from a moving aircraft. The voice recordings were later transcribed onto paper and into a database organized by year (1963-1979) or survey date (1989-present), zone, taxon, and number of individuals. These data were then compiled into annual reports that summarized observations by zone and year (1963-1965) or month (1975-present).

\section{Geospatial Data}

We created polygon shapefiles for the 12 (and 92) DAWR survey zones from historical records and satellite imagery (Supplementary Figure S1). Following the above survey methods, we generated a polygon that traced Guam's visible outer reef in Google Earth Pro (Google, 2013) and then clipped out the island of Guam using ArcMap 10.1 (ESRI, 2012). Using text narratives and hand-drawn maps from archived DAWR reports, we split this single polygon into the 12 (and 92) survey zones and calculated the planar area of each zone. For display purposes only, we added a 200-300 m seaward buffer to the zones, but we did not consider this part of the survey area or factor it into the planar area calculations.

To provide context for our results, we characterized the survey zones in terms of their benthic habitat, nearby human densities, and limitations on access and resource extraction. For each zone, we used existing benthic habitat data to estimate the area covered by the following habitat types: (i) coral reef and hard-bottom substrate covered predominantly by coral $(\mathrm{C})$, macroalgae $(\mathrm{M})$, turf $(\mathrm{T})$, or coralline algae $(\mathrm{CA})$; (ii) seagrass beds; and (iii) uncolonized sand flats (Burdick, 2006). To estimate nearby human densities, we summed the number of people in municipalities adjacent to each zone (U.S. Census Bureau, 2010), and scaled the total by zone area (Supplementary Figure S2). When one municipality bordered multiple zones, we divided the population amongst the zones proportionally based on the amount of coastline in each zone. Populations from inland municipalities were assigned to the closest zone. We categorized zones as follows: Low (562000 people $\mathrm{km}^{-2}$ ), Medium (2001-6000 people $\mathrm{km}^{-2}$ ), and High (6001-11,613 people $\mathrm{km}^{-2}$ ). Mapping the boundaries of Guam's five marine protected areas (MPAs) and all military lands allowed us to estimate the percentage of coastline associated with those features for each zone (Supplementary Figure S2). Additionally, we quantified the coastline for a third category-public and private lands-which included all nonmilitary lands not adjacent to MPAs. In Guam, MPAs typically prohibit all fishing and other resource extraction (analogous to IUCN protected area categories I-II), although there are some exceptions (Supplementary Figure S2). Military lands include U.S. military bases and airstrips, where both military and nonmilitary fishing is limited; in these areas, access to adjacent waters may be limited for those without a boat. Public and private lands contain shorelines that are legally accessible to the public (and as defined here, with no MPA restrictions on resource extraction), although cliffs may prevent convenient access in some places.

\section{Survey Analyses}

We analyzed the aerial survey data for temporal trends using five megafauna groupings: sea turtles, reef sharks, reef manta rays, small delphinids, and large delphinids (see Aerial Surveys subsection for species). As an index of abundance, we used observations (individuals) per survey (OPS). The OPS for 
years 1963-1979 was an annual mean, as the existing database combined all observations in those calendar years. For surveys occurring between 1989 and 2012, we calculated both annual and quarterly OPS values, as all survey observations were retained with corresponding survey dates. We used the quarterly mean in a time series trend analysis to maximize temporal resolution of the data while minimizing the error associated with small samples. We used the annual mean for all other analyses.

Using regression models and population growth rate (PGR) calculations, we quantified changes in OPS over time for each taxon. To describe general trends, we fit LOESS models (Cleveland and Devlin, 1988) to our calculated time series. Here, we used the annual OPS for 1963-1975 and quarterly OPS for 1989-2012. We used R (R Core Team., 2014) to estimate the models (using the "loess" function with a smoothing parameter of 0.7 and polynomial degree of 2) and compute means and 95\% confidence intervals. PGR is the annual per capita rate of increase, which we calculated as: PGR $=\left(\ln \left(y_{2}\right)-\ln \left(y_{1}\right)\right)$ / $\left(t_{2}-t_{1}\right)$, where $t_{1}$ and $t_{2}$ are sequential survey years, and $y_{1}$ and $y_{2}$ are the predicted mean values for those years from the LOESS model. We used this PGR calculation for all five taxa; however, for cetaceans, it is not a good approximation of actual population changes. Unlike the turtles and elasmobranchs included in this study, cetaceans do not depend on the reef to forage and thus the aerial surveys only sample a portion of their habitat. Therefore, the PGR calculation for cetaceans only reflects changes in annual observations, not the underlying populations, and we refer to it instead as the observation growth rate (OGR).

We also analyzed the survey data for spatial patterns and trends. For each taxon, we calculated the annual OPS density for each zone, and created a fishnet grid with survey zones on the $\mathrm{x}$-axis, years on the $\mathrm{y}$-axis, and color shading in the grid cells corresponding to the density for each year and zone. Grid rows show the spatial pattern in density for each year, while columns show the temporal trend for each zone. To illustrate the connection between the fishnet grids and the geographic distribution of the zones around Guam, we produced a map for each taxon for a single year, with zones shaded according to their density value for that year. We displayed the year with the highest annual OPS for each taxon.

Finally, we compared the spatially-explicit OPS densities to the benthic habitat and human-use attributes of the zones described above (Supplementary Figure S2). To provide a recent synoptic view of density for each zone, we calculated 5-year means (2008-2012, the most recent 5 years). We examined those mean densities with respect to the various zone characteristics to identify potential associations among them. For each taxon, we considered zone densities high if they exceeded the median value across all zones for that taxon, and low if they fell below it.

\section{Sea Turtle Abundance Estimation}

We estimated sea turtle population abundance from aerial survey data and recently recorded dive depth behavior. Our approach followed Seminoff et al. (2014), but was simplified because the Guam surveys are not line-transect surveys and thus observers do not record certain variables (e.g., declination angle to sighting and group size). The dive depth records came from Platform Terminal Transmitter (PTT), GPS-locating satellite tags (Wildlife Computers, MK-10, and SPLASH10-F-238A) deployed on 11 green and 2 hawksbills in 2014 in the Mariana Islands (unpublished data; methods described in Jones and Van Houtan, 2014). Turtles were hand-captured by free-diving from a small boat to 2-25 $\mathrm{m}$ depth to capture turtles resting or foraging on bottom substrate. The dive data records comprised 2682 diurnal $\mathrm{h}$ for green turtles and $534 \mathrm{~h}$ for hawksbills, which were separated into pre-determined depth bins. For greens, time spent at the surface ( $0 \mathrm{~m}$ bin) was $10.7 \%$ of total recorded behavior, and time at $>0-2 \mathrm{~m}$ depth was $12.5 \%$ (i.e., greens spent $23.2 \%$ of the time at $0-2 \mathrm{~m}$ ). For hawksbills, time at $0 \mathrm{~m}$ was $2.9 \%$ and time at $>0-$ $2 \mathrm{~m}$ was $2.7 \%$ (i.e., hawksbills spent $5.6 \%$ of the time at $0-2 \mathrm{~m}$ ). The remaining time was spent below $2 \mathrm{~m}$ depth, where aerial observers did not detect or record turtles.

Based on the in-water capture rates observed through the above tagging efforts, we estimated that $85 \%$ of sea turtles in Guam are green turtles, and $15 \%$ are hawksbills; the dominance of green turtles is corroborated by previous accounts (Pritchard, 1995; Wiles et al., 1995). These proportions have likely changed over time based on species-specific exploitation and recovery rates; thus, the assumption is likely less applicable going back in the time series. We used the following equation to estimate species abundance: $\mathrm{N}_{s, i}=\mathrm{OPS}_{i} \cdot \mathrm{P}_{s} \cdot \mathrm{T}_{s, d}{ }^{-1}$, where $\mathrm{N}_{s, i}$ is the abundance of species $s$ in year $i, \mathrm{OPS}_{i}$ is the annual mean observations per survey for year $i$ (32 years in 1963-2012), $\mathrm{P}_{s}$ is the proportion of species $s$ in the population, and $\mathrm{T}_{s, d}$ is the proportion of time that species $s$ spends at depth $d$. We produced a range of estimates by using two different assumptions: (1) turtles were visible only at the surface ( $0 \mathrm{~m}$ bin), and (2) turtles were visible down to $2 \mathrm{~m}$ (both $0 \mathrm{~m}$ and $0-2 \mathrm{~m}$ bins). Both scenarios also assume that observers detected all turtles present in the specified depth range. In reality, most of the observed turtles were at the surface, but an unknown portion were detected at $>0-2 \mathrm{~m}$ (typically diving from the surface). Additionally, aerial detection of turtles is likely not perfect for either depth range, and some turtles were probably missed. These estimates, then, provide a minimum range of the true abundance for each species on Guam's reefs.

The dive data were generated by biotelemetry research that was conducted in accordance with the Institutional Animal Care and Use Committee protocols of the U.S. National Marine Fisheries Service (Southwest/Pacific Islands 2011-04) and under the following permits: NMFS ESA10a1A 17022, USFWS Recovery Permit TE-72088A-0, and Guam Department of Agriculture Special Permit for Scientific Research SP2013-004.

\section{RESULTS}

DAWR completed 632 surveys in 32 years of a 50-year span (surveys year ${ }^{-1}$ : mean $=19.8, S D=5.1$ ), representing approximately $809 \mathrm{~h}$ of survey effort over the nearshore marine environment of Guam $\left(70.16 \mathrm{~km}^{2}\right)$. In total, surveyors recorded 10,622 turtle, 1026 shark, 60 manta ray, 7515 small delphinid, 
and 95 large delphinid observations. The aerial survey results displayed a variety of patterns in megafauna temporal trends, trend variability, abundance, and spatial distribution over time.

\section{Sea Turtles}

Turtle observations increased from 1963 to 2012 (Figure 1A) and varied spatially, with the highest densities occurring along the south, east, and north coasts, particularly in areas having low human density, reefs with coral cover, and either seagrass beds or an MPA (or both). OPS ranged from 1.1 to 44.6 across years $($ mean $=16.4, S D=12.5, C V=76 \%)$. PGR was relatively high across all years (mean $=0.07, S D=0.06, C V=90 \%$ ) and increased during 1989-2012, the most recent contiguous survey period (mean $=0.10, S D=0.04, C V=37 \%$ ). OPS was highest in 2010 (44.6 turtles per survey), when density reached 2.7 turtles $\mathrm{km}^{-2}$ in the Cocos Lagoon area (zone 8), but was less than 0.3 turtles $\mathrm{km}^{-2}$ elsewhere (Figure 1B). Prior to 2000 , density was $0-0.2$ turtles $\mathrm{km}^{-2}$ in zone 8 ; it increased dramatically to $0.4-2.7$ turtles $\mathrm{km}^{-2}$ after 2000 (Figure 1C). Most of the regional increase in turtles was driven by a local increase in this zone. After the 1970s, the west side (zones 1-7) generally had lower turtle densities than other areas (Figure 1C). Mean densities for 2008-2012 were highest in zones 8 (2.08 turtles $\mathrm{km}^{-2}$; reef, seagrass, and sandy habitat; low human density; MPA along 55\% of shoreline), 12 (0.37 turtles $\mathrm{km}^{-2}$; reef habitat; low/medium human density; MPA along $60 \%$ of shoreline; military lands along $65 \%$ of shoreline), and $9(0.33$ turtles $\mathrm{km}^{-2}$; reef, seagrass, and sandy habitat; low human density; Table 1). Mean abundance estimates for 2008-2012 were 138-299 greens and 101-196 hawksbills (Supplementary Table $\mathrm{S} 1)$; the low values assume turtles were detected down to $2 \mathrm{~m}$ and the high values assume detection only at the surface $(0$ $\mathrm{m})$. Actual abundances are likely closer to the high values, as most turtles were sighted at the surface. Supplementary Table S1 provides further summary statistics on abundance estimates for 1963-2012.

\section{Sharks}

Shark observations decreased from 1963 to 2012 (Figure 2A). Spatial patterns differed from those observed for turtles, but sharks similarly had the highest densities along the east and north coasts, where reefs with coral cover were the dominant habitat feature and human densities were low to medium. OPS ranged from 0.1 to 8.6 across years (mean $=1.7, S D=1.8$, $C V=107 \%$ ). PGR was negative across all years (mean $=$ $-0.03, S D=0.04, C V=138 \%$ ) but slightly lower for 19892012 (mean $=-0.02, S D=0.05, C V=200 \%$ ), with the highest OPS occurring in 1965 (8.6 sharks per survey), early in the time series. In 1965, densities were highest along the west coast (zones 1-4), reaching 0.42 sharks $\mathrm{km}^{-2}$ in zone 3;
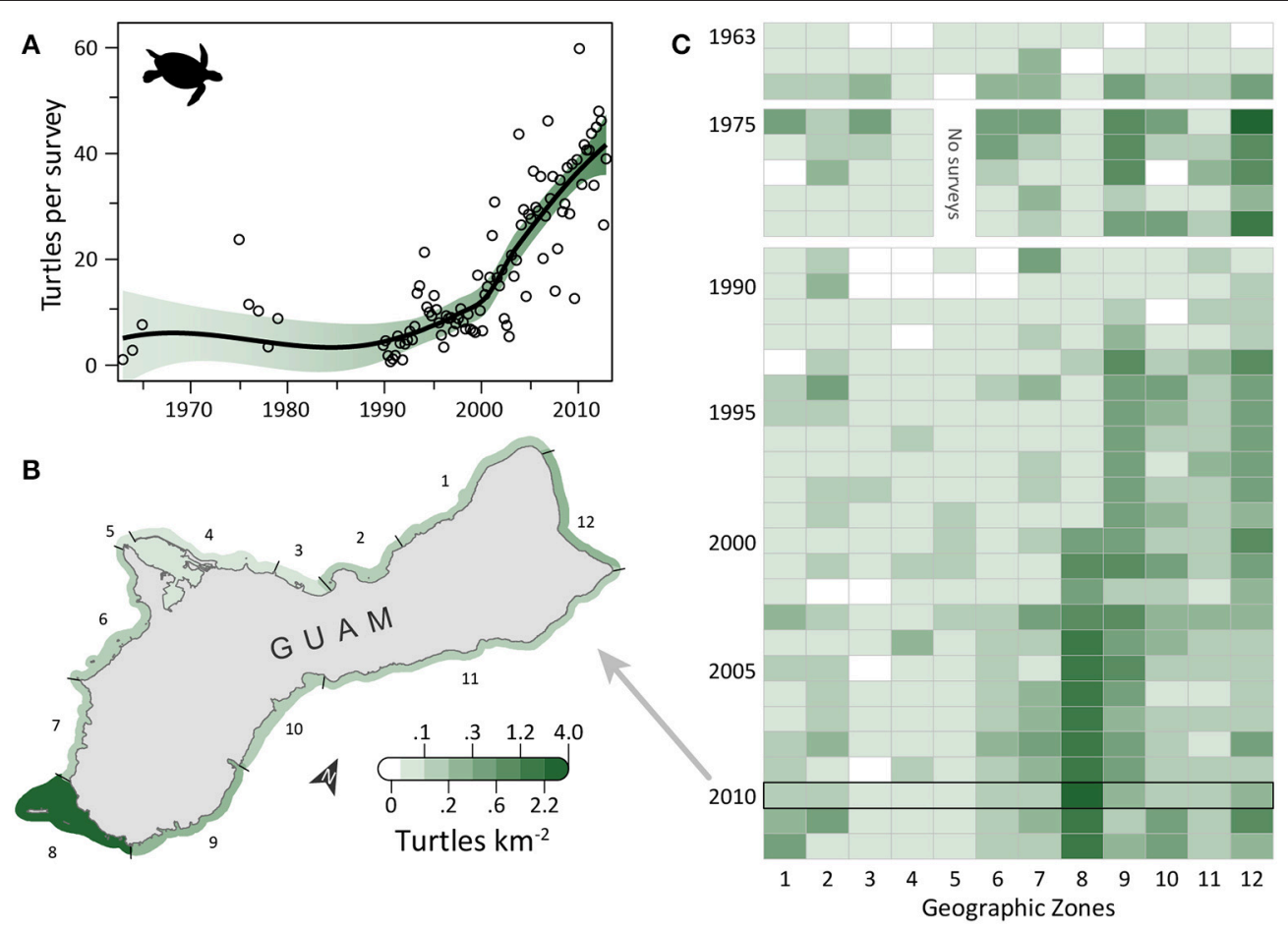

FIGURE 1 | Eight-fold increase in observed sea turtles on Guam's reefs in the last five decades. (A) Trend in turtle observations from semimonthly aerial surveys conducted by Guam Division of Aquatic and Wildlife Resources (DAWR). Open circles are annual or quarterly observations (turtles) per survey (OPS). Smoothed line is a model fit, with 95\% confidence interval shaded. Mean population growth rate (PGR) was $0.07(S D=0.06, C V=90 \%)$ since 1963 and $0.10(S D=$ $0.04, \mathrm{CV}=37 \%$ ) since 1989. (B) Map of 12 geographic survey zones; shading depicts observed densities for 2010 , when annual OPS was highest. (C) Trends in densities for the 12 zones. Zone 5 was closed to surveys in 1975-1979 due to military restrictions. The west coast (zones 1-7) generally had lower densities than the rest of Guam after the 1970s. The increase in zone 8 drives the overall increase observed in (A). 
TABLE 1 | Mean observed densities of five marine megafauna from aerial surveys of Guam, 2008-2012.

\begin{tabular}{|c|c|c|c|c|c|c|c|c|c|c|c|c|}
\hline Zone & Region & $\begin{array}{l}\text { Area } \\
\left(\mathrm{km}^{2}\right)\end{array}$ & Benthic habitat & $\begin{array}{l}\text { Human density } \\
\text { (people km-2) }\end{array}$ & MPAs & $\begin{array}{l}\text { Military } \\
\text { lands }\end{array}$ & $\begin{array}{c}\text { Public/Private } \\
\text { lands }\end{array}$ & $\begin{array}{l}\text { Turtles } \\
(n=474)\end{array}$ & $\begin{array}{l}\text { Sharks } \\
(n=42)\end{array}$ & $\begin{array}{l}\text { Mantas } \\
(n=15)\end{array}$ & $\begin{array}{l}\text { Sm. Delph. } \\
\qquad(n=25)\end{array}$ & $\begin{array}{l}\text { Lg. Delph. } \\
\qquad(n=3)\end{array}$ \\
\hline 1 & West & 3.87 & $\operatorname{Reef}(\mathrm{C}, \mathrm{T}, \mathrm{M})$ & High & - & $2 \%$ & $98 \%$ & 0.20 & 0.01 & 0.03 & 0.06 & 0.00 \\
\hline 2 & West & 3.10 & $\operatorname{Reef}(\mathrm{T}, \mathrm{C}, \mathrm{M})$ & Med.-High & $57 \%$ & $3 \%$ & $40 \%$ & 0.18 & 0.01 & 0.03 & 0.00 & 0.00 \\
\hline 3 & West & 2.66 & Reef (M, C), Seagrass & Med.-High & - & - & $100 \%$ & 0.03 & 0.00 & 0.00 & 0.00 & 0.00 \\
\hline 4 & West & 4.29 & $\operatorname{Reef}(\mathrm{C}, \mathrm{T}, \mathrm{M})$ & Low & $20 \%$ & - & $80 \%$ & 0.07 & $<0.01$ & 0.00 & 0.15 & 0.00 \\
\hline 5 & West & 15.70 & Sand, Reef $(C, M, T)$ & Low & $18 \%$ & $53 \%$ & $35 \%$ & 0.08 & $<0.01$ & $<0.01$ & 0.00 & 0.00 \\
\hline 6 & West & 6.10 & $\begin{array}{l}\text { Reef }(C, T, M) \text {, } \\
\text { Seagrass }\end{array}$ & Low-Med. & - & $45 \%$ & $55 \%$ & 0.17 & $<0.01$ & $<0.01$ & 0.12 & 0.02 \\
\hline 7 & West & 2.58 & $\begin{array}{l}\text { Reef }(M, T, C, C A) \text {, } \\
\text { Sand }\end{array}$ & Low & - & - & $100 \%$ & 0.23 & $<0.01$ & 0.00 & 0.57 & 0.11 \\
\hline 8 & South & 13.90 & $\begin{array}{l}\text { Reef }(C, M) \text {, Seagrass, } \\
\text { Sand }\end{array}$ & Low & $55 \%$ & - & $45 \%$ & 2.08 & 0.01 & $<0.01$ & 0.05 & 0.00 \\
\hline 9 & East & 3.49 & $\begin{array}{l}\text { Reef }(\mathrm{C}, \mathrm{M}, \mathrm{T}) \text {, } \\
\text { Seagrass, Sand }\end{array}$ & Low & - & - & $100 \%$ & 0.33 & 0.06 & 0.00 & 0.03 & 0.00 \\
\hline 10 & East & 4.27 & $\operatorname{Reef}(\mathrm{C}, \mathrm{M}, \mathrm{T})$ & Med. & - & - & $100 \%$ & 0.24 & 0.02 & 0.00 & 0.00 & 0.00 \\
\hline 11 & East & 7.20 & $\begin{array}{l}\text { Reef }(C, T, C A, M) \text {, } \\
\text { Sand }\end{array}$ & Low-Med. & $23 \%$ & $24 \%$ & $76 \%$ & 0.12 & 0.01 & 0.00 & 0.18 & 0.00 \\
\hline 12 & North & 3.00 & Reef $(\mathrm{C}, \mathrm{T}, \mathrm{CA})$ & Low-Med. & $60 \%$ & $65 \%$ & $35 \%$ & 0.37 & 0.02 & 0.00 & 0.11 & 0.07 \\
\hline All & Guam & 70.16 & Reef, Seagrass, Sand & 2271 & $17 \%$ & $21 \%$ & $67 \%$ & 0.54 & 0.01 & $<0.01$ & 0.08 & $<0.01$ \\
\hline
\end{tabular}

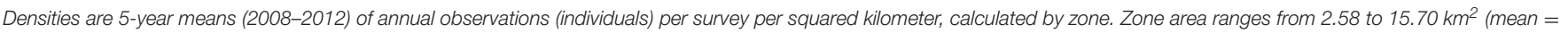

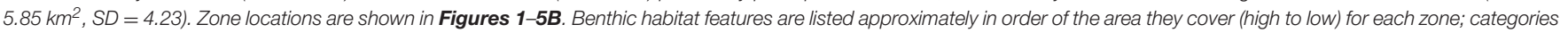

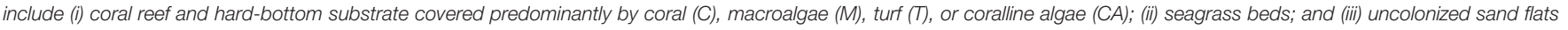

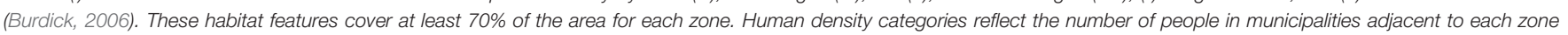

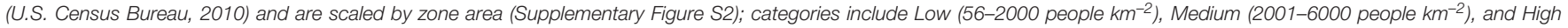

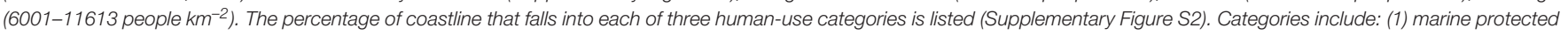

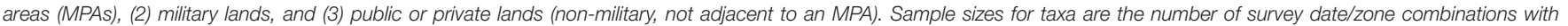

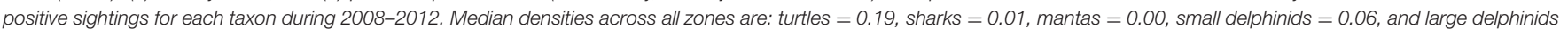

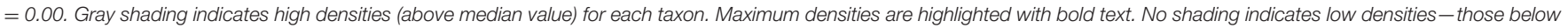

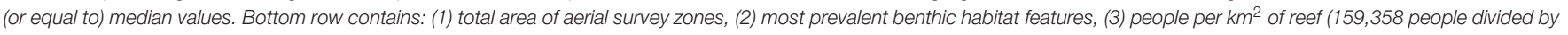

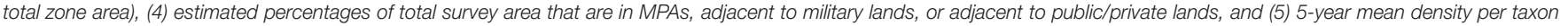
(all zones).

densities were $0-0.16$ sharks $\mathrm{km}^{-2}$ elsewhere, with no sharks observed in Apra Harbor (zone 5) (Figure 2B). After 1976, observations on the west coast became more sporadic and densities generally decreased (Figure 2C). On the east coast (zones 9-11), densities remained relatively high through the early 1990s, and then decreased slightly. Mean densities for 2008-2012 were highest in zones 9 (0.06 sharks $\mathrm{km}^{-2}$; reef, seagrass, and sandy habitat; low human density), 12 (0.02 sharks $\mathrm{km}^{-2}$; reef habitat; low/medium human density; MPA along $60 \%$ of shoreline; military lands along $65 \%$ of shoreline), and 10 (0.02 sharks $\mathrm{km}^{-2}$; reef habitat; medium human density; Table 1).

\section{Manta Rays}

Manta ray observations were low, but increased slightly over time (Figure 3A) and became locally concentrated in the northwest, an area dominated by reef habitat and containing an MPA. OPS ranged from 0 to 0.57 across years (mean $=0.12, S D=0.14$, $C V=116 \%)$. PGR was relatively high, but with high variability due to the low number of observations (mean $=0.19, S D=$ $0.61, C V=321 \%)$. OPS was highest in 2010 (0.57 mantas per survey), when density reached $0.06-0.09$ mantas $\mathrm{km}^{-2}$ in zones 1-2 along the northwest coast (Figure 3B). Since 2008, nearly all observations have occurred in the northwest, though there were a few observations in the southwest (zones 5-6, and 8) (Figure 3C). This pattern contrasts with earlier years, when observations were scattered throughout the zones (Figure 3C). Mean densities for 2008-2012 were highest in zones 2 (0.03 mantas $\mathrm{km}^{-2}$; reef habitat; medium/high human density; MPA along $57 \%$ of shoreline; military land along $3 \%$ of shoreline) and 1 (0.03 mantas $\mathrm{km}^{-2}$; reef habitat; high human density; military land along $2 \%$ of shoreline; Table $\mathbf{1}$ ).

\section{Small Delphinids}

Small delphinid observations fluctuated over time (Figure 4A) and space, with the highest densities and most consistent sightings along the southwest and northeast coasts, where reefs and sand dominated the benthic habitat and human densities were relatively low. OPS ranged from 0 to 38.2 across years (mean $=13.5, S D=10.6, C V=79 \%)$. OGR varied over time; it was negative in 1978-1989 (mean $=-0.22, S D=$ $0.06, C V=28 \%$; but note there are only 3 points in this period, Figure 4A) and 1999-2009 (mean $=-0.15, S D=0.07$, $C V=44 \%$ ), and positive in 1990-1998 (mean $=0.35, S D=$ $0.30, C V=87 \%$ ) and 2010-2012 (mean $=0.06, S D=0.03$, $C V=52 \%$ ). Due to these changes in the direction of OGR, its variability across all years was extremely high (mean $=0.05, S D$ $=0.30, C V=611 \%$ ). OPS was highest in 2001, when density 

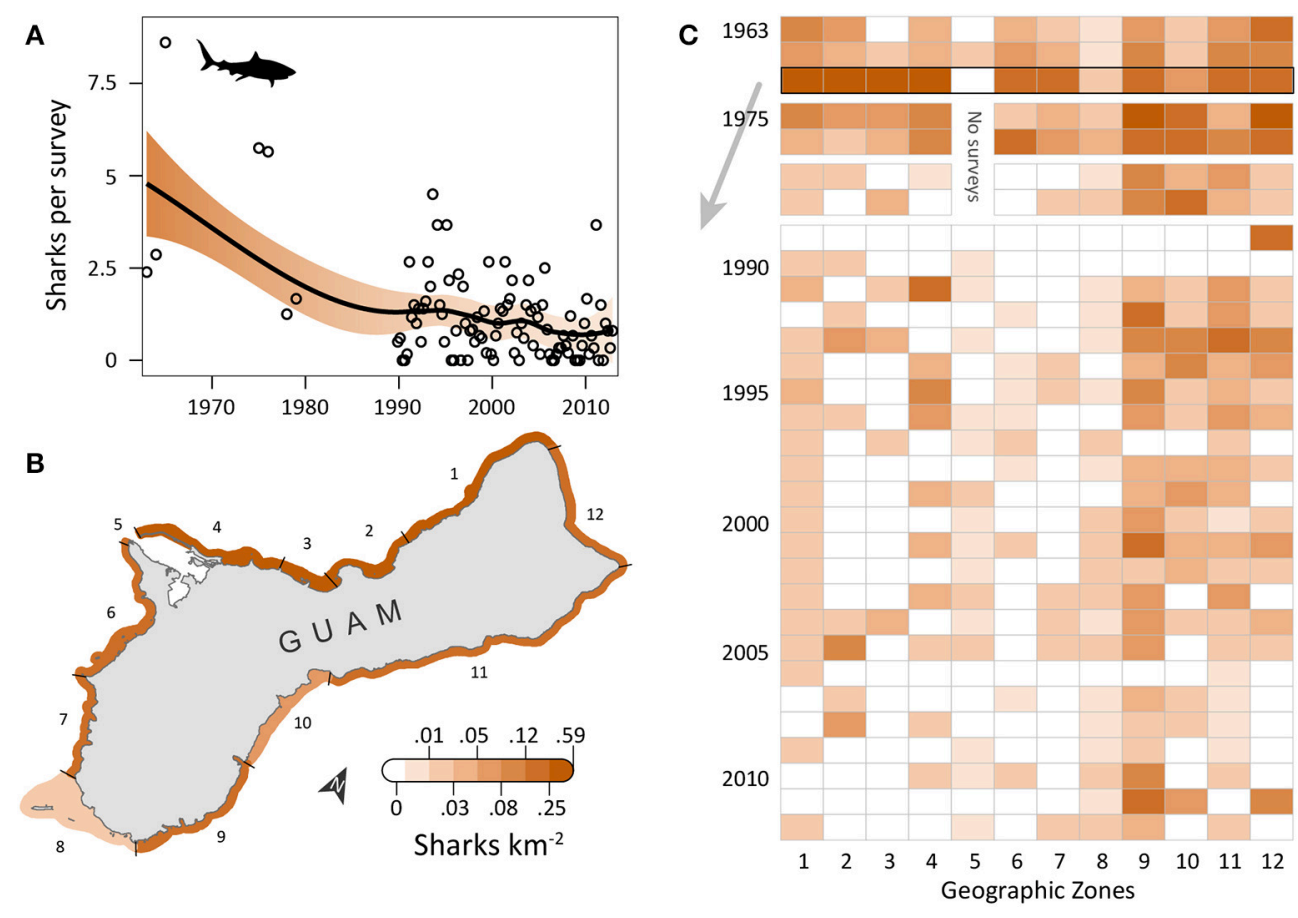

FIGURE 2 | Five-fold decline in reef shark observations around Guam in the last five decades. (A) Trend in shark observations from aerial surveys conducted semimonthly by Guam Division of Aquatic and Wildlife Resources (DAWR). Observations (sharks) per survey (OPS) by year or quarter are indicated by open circles. Smooth trend line and shaded 95\% confidence interval are from a model fit. Since 1963, mean population growth rate (PGR) was -0.03 (SD $=0.04, C V=138 \%)$. (B) Map of observed densities for 1965, when annual OPS was highest; densities were particularly high for western zones 1-4, especially compared to densities there in later years. (C) After 1976, west coast observations became sporadic and densities generally decreased. On the east coast (zones 9-11), densities were high through the 1990s, then decreased slightly, but remained generally higher than west coast densities. No surveys occurred in zone 5 in 1975-1979 due to military restrictions.

reached 3.47 small delphinids $\mathrm{km}^{-2}$ along the northeast coast (zone 11) (Figure 4B). Intermediate densities (0.06-1.89 small delphinids $\mathrm{km}^{-2}$ ) occurred in most other areas in 2001, although no small delphinids were observed in zones 3 and 5 in the west, 8 in the south, and 10 in the east (Figure 4B). Over time, historically high densities in the north (zone 12) and northeast (zone 11) decreased (Figure 4C). On the west coast, densities were consistently low in zones 3-5, while they were frequently intermediate in zones 1 and 7. Densities were high in many zones during the 1990s and early 2000s, after which they decreased and became more localized to fewer zones $(7,8$, and 11$)$. The highest mean densities for 2008-2012 occurred in zones 7 (0.57 small delphinids $\mathrm{km}^{-2}$; reef and sandy habitat; low human density), 11 (0.18 small delphinids $\mathrm{km}^{-2}$; reef and sandy habitat; low/medium human density; MPA along $23 \%$ of shoreline; military lands along $24 \%$ of shoreline $)$ and 4 ( 0.15 small delphinids $\mathrm{km}^{-2}$; reef habitat; low human density; MPA along 20\% of shoreline; Table $\mathbf{1}$ ).

\section{Large Delphinids}

Large delphinid observations were low, but increased slightly over time (Figure 5A) and were most dense along the southwest and north coasts. OPS ranged from 0 to 1.43 across years (mean $=0.20, S D=0.39, C V=197 \%$ ). OGR and its variability were high due to the low number of observations (mean $=0.16, S D$ $=0.83, C V=508 \%$ ); this OGR is particularly unreliable in a population context, as it may reflect up to four species across only six total encounters, and the survey area only captures a small portion of the habitat range for those species. OPS was highest in 2010 (1.43 large delphinids per survey), when density was 0.55 large delphinids $\mathrm{km}^{-2}$ in the southwest (zone 7) and 0 elsewhere (Figure 5B). Large delphinids were never observed in zones $1-5$ on the west coast or zone 10 on the east coast (Figure 5C). Density was only positive in one zone per year, and only in the south (zones 6-9) and northeast (zones 11-12). Since 2007, observations have been slightly higher (mean density of 0.014 vs. 0.001 prior to 2007) and more frequent (Figure 5C). Mean densities for 2008-2012 were highest in zones 7 (0.11 large delphinids $\mathrm{km}^{-2}$; reef and sandy habitat; low human density), 12 (0.07 large delphinids $\mathrm{km}^{-2}$; reef habitat; low/medium human density; MPA along $60 \%$ of shoreline; military lands along $65 \%$ of shoreline), and 6 (0.02 large delphinids $\mathrm{km}^{-2}$; reef and seagrass habitat; low/medium human density; military lands along $45 \%$ of shoreline; Table 1).

\section{DISCUSSION}

Five decades of aerial surveys of Guam's reefs provide important insights into changes in marine megafauna populations. Of the five taxa we examined, turtles were the most widely distributed and consistently recorded, yet their dramatic increase was 


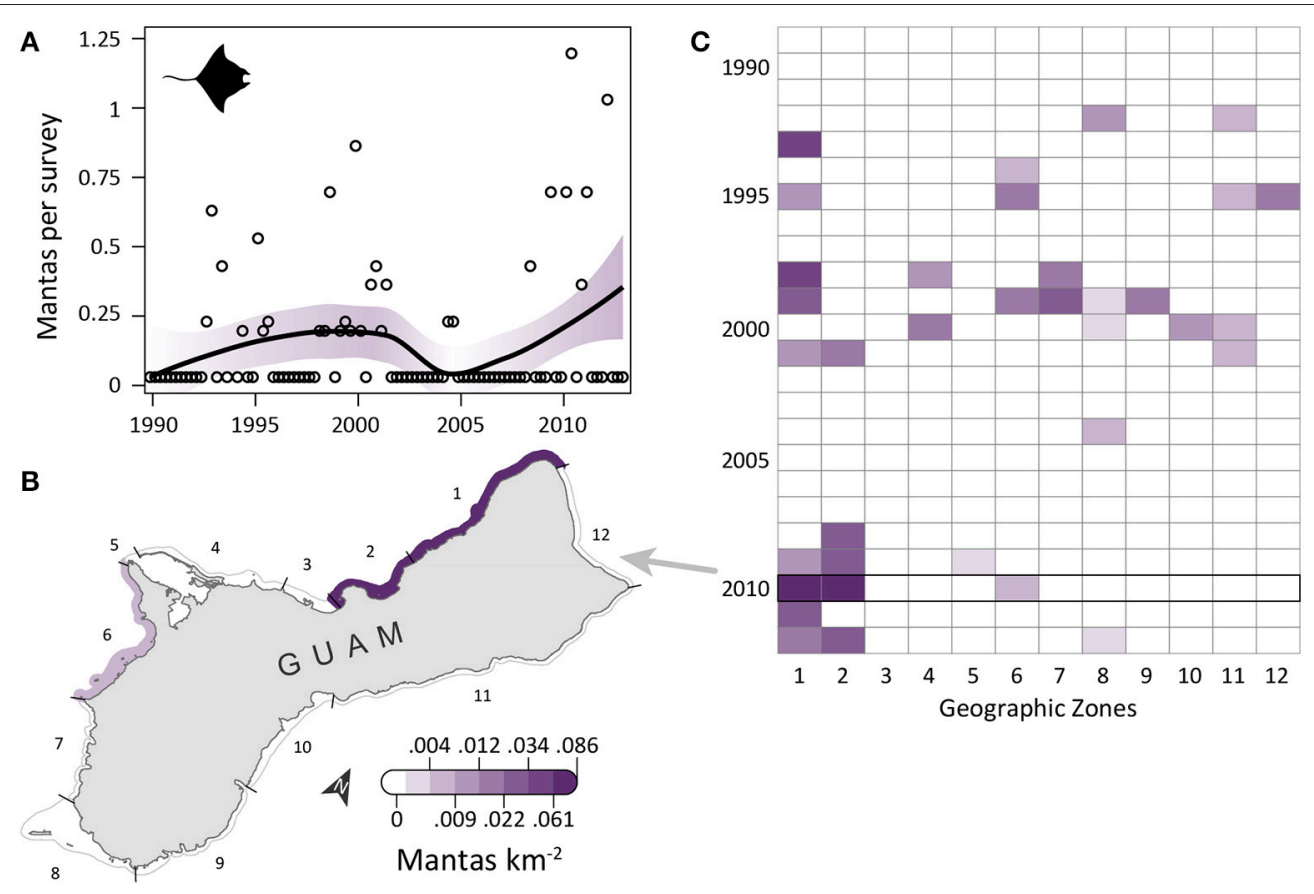

FIGURE 3 | Infrequent, increasingly aggregated manta ray observations on Guam's reefs since 1989. (A) Trend in manta ray observations from semimonthly aerial surveys conducted by Guam Division of Aquatic and Wildlife Resources (DAWR). Observations (manta rays) per survey (OPS) by quarter are depicted with open circles. Model fit with shaded 95\% confidence interval suggests observations became slightly more common over time. Mean population growth rate (PGR) was 0.19 $(S D=0.61, C V=321 \%)$, but should be viewed with caution due to the low number of observations. (B) Map of observed densities for 2010, the year with the highest annual OPS; densities were high in the northwest (zones 1-2) and low elsewhere. (C) Since 2008, most observations were in the northwest, with a few sightings in the southwest (zones 5, 6, and 8).

constrained to a single location. Shark numbers declined sharply from early survey levels. Manta rays were infrequently seen, but observations increased slightly over time. Small delphinid numbers fluctuated, with alternating regimes of decrease and increase. Large delphinid observations were historically rare, but increased slightly in the last decade. Each taxon had idiosyncratic spatial patterns, and was often clustered in specific zones of high densities. For turtles, sharks, and manta rays, the highest densities (2008-2012) were in zones that had coral reefs as dominant habitat features and: (i) seagrass beds and sand flats as additional habitat features (turtles and sharks), (ii) low human densities (turtles and sharks), (iii) an MPA along $>50 \%$ of the shoreline (turtles and manta rays), and (iv) an MPA along $>50 \%$ of the adjacent zone's shoreline (sharks and manta rays).

The observed increase in sea turtles in Guam is consistent with the historical shift from extraction to conservation protection. Previous studies have linked the low abundance of sea turtle populations from 1950 to 1980 to historical harvests (Groombridge et al., 1989; Van Houtan and Kittinger, 2014) that occurred throughout the Pacific Islands. But sea turtle populations have been documented to rebound with conservation protections (e.g., Hawaii: Balazs and Chaloupka, 2004); Costa Rica: Troëng and Rankin, 2005; and Ascension Island: Broderick et al., 2006). The post-1999 increase we observed occurred almost exclusively in zone 8 , which contains the Achang Reef Flat Preserve, a no-take MPA established in 1997 and fully enforced by 2001 (Tupper, 2007; Allen and Bartram, 2008; Supplementary Figure S2). After 1999, observations were nearly 30 times higher in zone 8 but only 12\% higher elsewhere (Supplementary Figure S3). Mangroves, seagrass beds, coral reefs, sand flats, and reef channels in this area provide quality foraging and resting habitat for turtles (Tupper, 2007). A recent global analysis showed satellite-tracked green turtles disproportionately aggregate in MPAs (Scott et al., 2012), which is consistent with our results. However, our findings contrast with those of Christianen et al. (2014), who found severely degraded seagrass beds inside a 10-year old MPA where turtles aggregated.

Our calculated rate of increase in Guam sea turtles corroborates other regional time series, providing important information for this data deficient region. Though the biogeography and abundance of hawksbill populations is poorly understood, the recent global green turtle status review placed Guam within the Central West Pacific (CWP) distinct population segment (DPS) (Seminoff et al., 2015). This DPS is spatially bounded by the Asian continent to the west and north, the Solomon Islands to the south, the Marshall Islands in the east, and Palau in the west. The only long-term population time series from this DPS-from Chichijima in Ogasawara, Japan-had an annual growth rate of $6.8 \%$ (Chaloupka et al., 

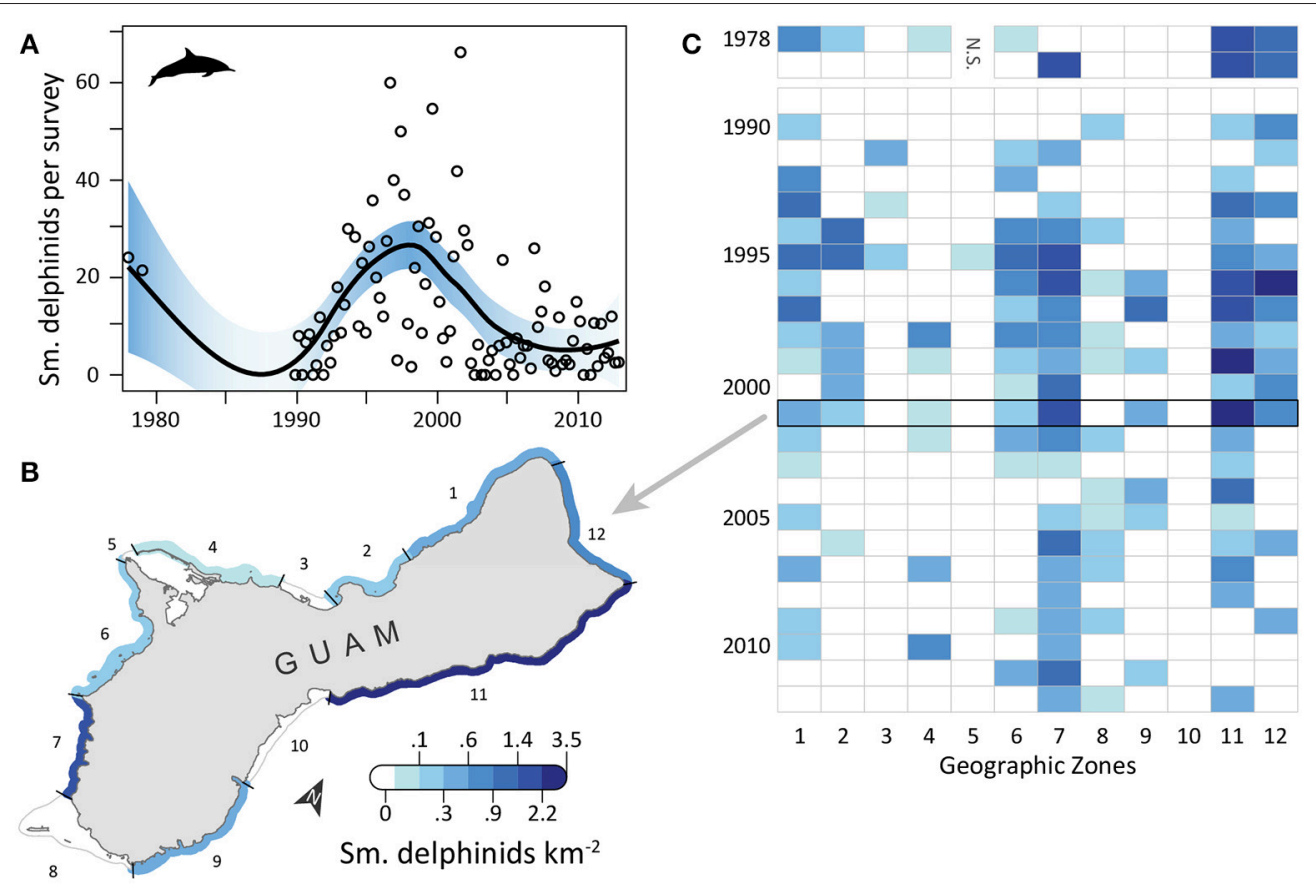

FIGURE 4 | Fluctuating trend in small delphinid observations around Guam since 1978. (A) Trend in small delphinid observations from semimonthly aerial surveys conducted by Guam Division of Aquatic and Wildlife Resources (DAWR). Open circles are observations (small delphinids) per survey (OPS) by year or quarter. Model fit with shaded 95\% confidence interval shows that observations were highly variable over the time series. Correspondingly, mean observation growth rate (OGR) was negative in 1978-1989 (mean $=-0.22, S D=0.06, C V=28 \%$ ) and 1999-2009 ( mean $=-0.15, S D=0.07, C V=44 \%$ ) and positive in 1990-1998 (mean $=0.35, S D=0.30, C V=87 \%$ ) and 2010-2012 (mean =0.06, SD =0.03, CV = 52\%). (B) Map of observed densities for 2001, the year with the highest annual OPS. Density was highest in zone 11 and lowest in zones 3, 5, 8, and 10. (C) The highest, most widespread positive densities were observed throughout the 1990s and early 2000s. Densities decreased over time in zones 1, 2, 6, 11, and 12. Observations were rare in zones 3-5, and never occurred in zone 10. Military restrictions prohibited surveys in zone 5 in 1978-1979.

2008; Seminoff et al., 2015), similar to the $7.0 \%$ we observed. The DPS is currently proposed to be listed as endangered under the U.S. Endangered Species Act (Federal Register, 2015), due to low population abundance and various threats facing green turtles in this region (Seminoff et al., 2015). As green turtles in Guam are primarily juveniles (Jones and Van Houtan, 2014) that are likely from distant rookeries (Dutton et al., 2014), the increasing populations in Guam may be benefiting from a host of influences, local and otherwise. Such influences may include oceanographic conditions (Solow et al., 2002; Hawkes et al., 2009; Van Houtan and Halley, 2011), changes in fisheries bycatch (Lewison et al., 2004), and nesting beach protections (Chaloupka et al., 2008). Thus it is difficult to attribute the increase in Guam to a particular cause, though local factors likely play a role. Future efforts to resolve the spatial population structure of sea turtles in Guam will help to clarify these effects.

The decline in sharks is consistent with widely observed patterns of chronic heavy extraction, few protections, and expanding human impacts. A variety of data streams point to industrial fisheries as causing large-scale declines in pelagic sharks (Baum et al., 2003; Myers and Worm, 2003; Baum and Myers, 2004; Ferretti et al., 2008). Similar declines have been documented in reef ecosystems elsewhere where human impacts are high and conservation insufficient (e.g., Australia: Robbins et al., 2006; Caribbean: Ward-Paige et al., 2010). Data from in-water surveys (Friedlander and DeMartini, 2002; Robbins et al., 2006; Sandin et al., 2008; Williams et al., 2011; Nadon et al., 2012), cultural ephemera (McClenachan, 2009a), archeological and historical records (Pandolfi et al., 2003), observations by trained scuba divers (Ward-Paige et al., 2010), and museum collections (Drew et al., 2015) all point to declines in reef sharks. Though overfishing is also recognized as a primary driver (directly and indirectly) of these declines, a general degradation of reef ecosystems (Pandolfi et al., 2003; Robbins et al., 2006; Ward-Paige et al., 2010; Drew et al., 2015) likely exacerbates these effects. Across the Pacific, studies show heavily-impacted reefs have fewer predatory fish, lower overall fish biomass, and fewer reef-building organisms than remote ecosystems (Friedlander and DeMartini, 2002; Sandin et al., 2008; Williams et al., 2011). The decrease in shark densities we observed was primarily along the west coast, where human development, tourism, and fishing are most concentrated (Tupper, 2007; van Beukering et al., 2007; Allen and Bartram, 2008). Cliff areas and rougher seas on the east coast (windward side) may limit fishing and other activities, possibly contributing to higher shark densities. MPAs to the north and south, moreover, create limited-take buffers (Supplementary Figure S2). Combined, these features may positively impact shark populations by maintaining lower levels of human impact. Our results provide evidence that Guam, the most populated island in Micronesia (Porter et al., 


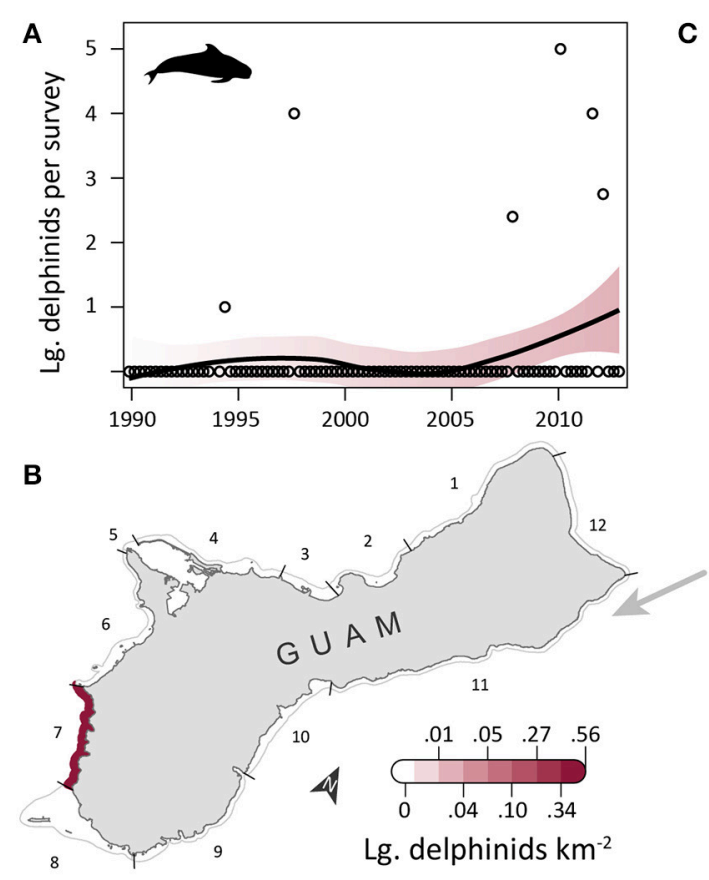

C

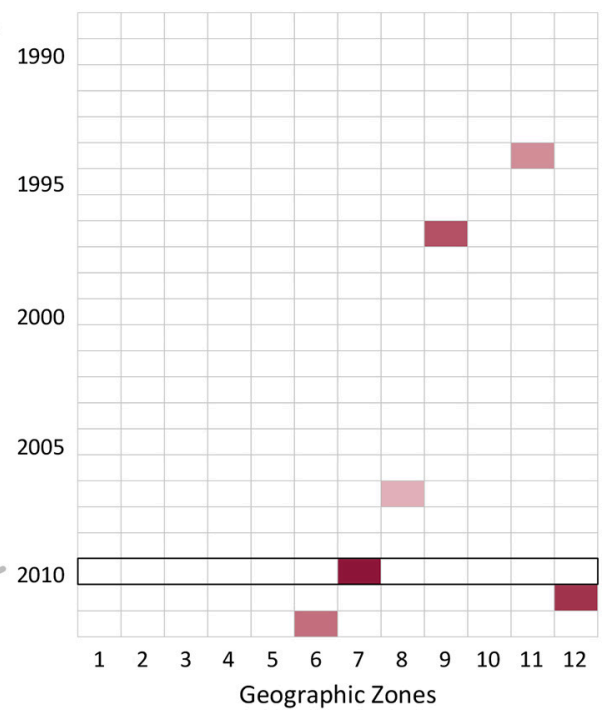

FIGURE 5 | Rare, possibly increasing observations of large delphinids in coastal waters of Guam since 1989. (A) Trend in large delphinid observations from aerial surveys conducted semimonthly by Guam Division of Aquatic and Wildlife Resources (DAWR). Open circles indicate quarterly observations (individuals) per survey (OPS). Smoothed line and shading are from a model fit with 95\% confidence interval. Observations were rare, with no large delphinids recorded in $75 \%$ of survey years. (B) Map of observed densities for 2010, the year with the highest OPS. Density was positive in the southwest (zone 7), but zero elsewhere. (C) No large delphinids were observed in zones 1-5 along the west coast or in zone 10 on the east coast. Large delphinids were recorded in a maximum of one zone per year (zones 6-9 and 11-12). Sightings appear to be more frequent since 2007.

2005), follows the pattern of reef shark decline seen on other reefs worldwide. Interestingly, the $84 \%$ decrease we observed from 1963 to 2012 (from our LOESS model) is not far from the $94 \%$ shark decline (from a pristine baseline) estimated for the Mariana Islands from ecosystem models and towed-diver survey data (Nadon et al., 2012). The aerial surveys began in 1963, when conditions on Guam were already less than pristine, which may explain some of the difference in these estimates. Nonetheless, our results provide further support for the shark decline estimated by Nadon et al. (2012).

Trends for manta rays and cetaceans were less informative, but the spatial patterns provide insights into their distributions around Guam. The aggregation of manta rays in the northwest co-occurs with the Tumon Bay Marine Preserve (a limitedtake MPA). At this site, manta rays were documented feeding on gamete clouds of spawning surgeonfish on the reef slope (Hartup et al., 2013). Unlike the other taxa, cetaceans do not depend on the reefs to forage. The fluctuating temporal trend in small delphinid presence could be due to inter-annual variability in the proximity of their prey to the coast. And though we believe most of the small delphinid sightings are spinner dolphins, observations of other species could obscure the observed geographic or temporal signals. For both small and large delphinids, the highest densities generally occur in the southwest and north/northeast, where reefs and sand flats are dominant habitat features and human density is relatively low; the Pati Point Preserve (a limited-take MPA adjacent to military lands) is also located in the northeast (Supplementary Figure S2). This suggests that cetaceans may prefer areas with lower levels of human activity. However, the mechanism driving these observations could be more related to oceanographic features, such as bathymetry and currents. These patterns deserve further attention.

Changes in survey techniques, detectability issues, and diving behavior may affect our estimates of survey densities over the course of the study. We followed best practices recommended for addressing confounding factors when using historical ecology approaches (McClenachan et al., 2015), particularly in dealing with species identification, variation in sampling effort, and data gaps. For example, we aggregated species into broad taxonomic groups, even though observers were fairly certain they knew which species they observed. A disadvantage of this method is that trends for individual species are obscured. The shift from a helicopter in the 1960s to fixed-wing aircraft could have influenced both observer visibility and airspeed, but these influences are uncertain. We assumed observers detected all surface animals, but they may actually miss animals, biasing abundance estimates (Marsh and Sinclair, 1989; Seminoff et al., 2014; Fuentes et al., 2015). Bathymetric differences also may make detection easier in some geographic areas than others. Surface glare, cloud cover, and wave height may affect detectability; we investigated the latter two and did not find relationships with the number of animals observed. Further, observers may have become primed to expect animals in certain 
areas and not others, based on previous experience or knowledge of MPAs (Rocliffe et al., Unpublished data). They may miss animals when fishing activity is high, as monitoring fishing is the primary objective. This risk may be minimized, however, through the use of highly experienced observers and voice recorders. Our calculation of turtle abundances could be sensitive to two conversion factors: (1) proportion of time spent at the surface (availability), which may be impacted by the presence of tags (Jones et al., 2013), and (2) proportions of species in the population.

Future studies could build on our analyses and strengthen our conclusions. First, digital video recorders or drones could be used to calibrate aerial observers and potentially conduct surveys. Calibration could provide useful data on observerspecific detection biases, and also validate the aerial surveys as effective means of collecting data on these taxa. These surveys comprise a unique time series; confirming their use as a monitoring tool is important. Low-cost "conservation drones" have been successfully developed and used in tropical forests to survey human activities and large animal species (Koh and Wich, 2012) and could be an effective option for monitoring reef systems. Second, standardized line-transect surveys (using aerial vehicles, manned or autonomous, or boats) could be conducted separately for each taxon, with methods optimized for each. Such surveys would allow researchers to spend more time in each area. For cetaceans, the geographic scope could be expanded to include areas beyond the reefs. For the reef-associated taxa (turtles, sharks, manta rays), studies could be designed at spatial scales appropriate to compare densities inside and outside the MPAs; this would help determine whether they are having an impact. The 92-zone system could be used for spatial analyses. Third, future studies could examine protections, access (e.g., public shoreline access locations), and extraction as potential drivers of reef fauna densities in Guam by relating metrics of human activity (e.g., population, fishing, or land use) to those densities. Our study provided some context for this line of investigation, but did not attempt to identify cause-and-effect relationships. Finally, our continued efforts to capture and tag turtles will decrease uncertainty in our abundance estimates by improving data on the two conversion factors. Efforts to tag reef sharks and manta rays would provide information on the availability of those taxa at the surface, thus enabling estimates of abundance.

In this study, we analyzed five decades of aerial survey data from Guam to understand trends in abundance and distribution for five marine megafauna, all of which are of conservation concern and data deficient in this region. We showed that the observed foraging population of turtles increased eight-fold, mostly in one geographic area with optimal habitat and MPA

\section{REFERENCES}

Allen, S., and Bartram, P. (2008). Guam as a Fishing Community. Administrative Report H-08-01. Honolulu, HI: Pacific Islands Fisheries Science Center, National Marine Fisheries Service, NOAA.

Amesbury, J. R., and Hunter-Anderson, R. L. (2003). Review of Archaeological and Historical Data Concerning Reef Fishing in the US Flag Islands of Micronesia: status, while the observed reef shark population decreased 5-fold, mostly in areas proximate to human population centers. Trends for manta rays and cetaceans were less informative, but each taxon had geographic foci. Protections in the region may be working to recover turtle populations, but failing (or have not yet had sufficient time) to recover overfished shark populations. Long-term analyses of vulnerable marine megafauna in this datapoor region are uncommon and should be used to guide more focused studies. Furthermore, historical data and analyses such as these should be considered in regional conservation and management planning, as they provide important insights into population and ecosystem changes, and baselines for calibrating recovery goals (Van Houtan et al., 2012; Kittinger et al., 2013; McClenachan et al., 2015; Thurstan et al., 2015).

\section{AUTHOR CONTRIBUTIONS}

SM and KV designed the study. SW, JB, BT, JG, and CA collected and maintained aerial data. TJ, SW, and JB collected turtle dive data. BT, KV, and SM digitized and quality-checked aerial data. TJ and KV quality-checked dive data. SM and KV analyzed data, prepared figures, and wrote the manuscript. All authors reviewed the manuscript.

\section{FUNDING}

A portion of this research was funded by the Navy Commander, U.S. Pacific Fleet and the Naval Facilities Engineering Command (MIPR \#N00070-13-MP-4C261).

\section{ACKNOWLEDGMENTS}

L. Mukai, C. Luecken, A. Soutar, and M. Suydam provided logistical support to SM for the NRC RAP fellowship. J. Rivers, M. Kawai, S. Hakala, J. Whitaker, and E. Yago provided administrative support for the Navy contract to KV. G. Balazs, E. Oleson, S. Kolinski, M. Hill, A. Bendlin, A. Bradford, R. Hensley, G. Davis, F. Parrish, and two reviewers provided constructive comments on earlier versions of this manuscript. We thank all DAWR staff who contributed to the aerial surveys over the years.

\section{SUPPLEMENTARY MATERIAL}

The Supplementary Material for this article can be found online at: http://journal.frontiersin.org/article/10.3389/fmars. 2015.00116 10.1016/j.biocon.2003.08.008

Ban, N. C., Hansen, G. J. A., Jones, M., and Vincent, A. C. J. (2009). Systematic marine conservation planning in data-poor regions: Socioeconomic 
data is essential. Marine Policy 33, 794-800. doi: 10.1016/j.marpol.2009. 02.011

Baum, J. K., and Myers, R. A. (2004). Shifting baselines and the decline of pelagic sharks in the Gulf of Mexico. Ecol. Lett. 7, 135-145. doi: 10.1111/j.14610248.2003.00564.x

Baum, J. K., Myers, R. A., Kehler, D. G., Worm, B., Harley, S. J., and Doherty, P. A. (2003). Collapse and conservation of shark populations in the Northwest Atlantic. Science 299, 389-392. doi: 10.1126/science. 1079777

Broderick, A. C., Frauenstein, R., Glen, F., Hays, G. C., Jackson, A. L., Pelembe, T., et al. (2006). Are green turtles globally endangered? Glob. Ecol. Biogeogr. 15, 21-26. doi: 10.1111/j.1466-822X.2006.00195.X

Brown, J. H., Whitham, T. G., Ernest, S. K., and Gehring, C. A. (2001). Complex species interactions and the dynamics of ecological systems: long-term experiments. Science 293, 643-650. doi: 10.1126/science.293. 5530.643

Burdick, D. R. (2006). Guam Coastal Atlas Benthic Habitat Data (GIS Layer). University of Guam Marine Laboratory \& NOAA Pacific Islands Fisheries Science Center. Available online at: http://www.guammarinelab.com/ coastal.atlas/data/Guam_Coastal_Atlas_Benthic_Habitat_Data_Metadata.htm

Chaloupka, M., Bjorndal, K. A., Balazs, G. H., Bolten, A. B., Ehrhart, L. M., Limpus, C. J., et al. (2008). Encouraging outlook for recovery of a once severely exploited marine megaherbivore. Glob. Ecol. Biogeogr. 17, 297-304. doi: 10.1111/j.1466-8238.2007.00367.x

Christianen, M. J., Herman, P. M., Bouma, T. J., Lamers, L. P., van Katwijk, M. M., van der Heide, T., et al. (2014). Habitat collapse due to overgrazing threatens turtle conservation in marine protected areas. Proc. R. Soc. Lond. B Biol. Sci. 281:20132890. doi: 10.1098/rspb.2013.2890

Cleveland, W. S., and Devlin, S. J. (1988). Locally weighted regression: an approach to regression analysis by local fitting. J. Am. Statist. Assoc. 83, 596-610. doi: 10.1080/01621459.1988.10478639

Drew, J. A., Amatangelo, K. L., and Hufbauer, R. A. (2015). Quantifying the Human Impacts on Papua New Guinea Reef Fish Communities across Space and Time. PLoS ONE 10:e0140682. doi: 10.1371/journal.pone.0140682

Dulvy, N. K., Baum, J. K., Clarke, S., Compagno, L. J. V., Cortés, E., Domingo, A., et al. (2008). You can swim but you can't hide: the global status and conservation of oceanic pelagic sharks and rays. Aquat. Conserv. 18, 459-482. doi: $10.1002 /$ aqc. 975

Dutton, P. H., Jensen, M. P., Frutchey, K., Frey, A., LaCasella, E., Balazs, G. H., et al. (2014). Genetic stock structure of green turtle (Chelonia mydas) nesting populations across the Pacific islands. Pacific Sci. 68, 451-464. doi: 10.2984/68.4.1

ESRI (2012). ArcMap 10.1 Desktop. Redlands, CA: Environmental Systems Research Institute Inc.

Federal Register (2015). Endangered and Threatened Species; Identification and Proposed Listing of Eleven Distinct Population Segments of Green Sea Turtles (Chelonia mydas) as Endangered or Threatened and Revision of Current Listings, Vol. 80. Washington, DC: NOAA Fisheries and US Fish and Wildlife Service.

Ferretti, F., Myers, R. A., Serena, F., and Lotze, H. K. (2008). Loss of large predatory sharks from the Mediterranean Sea. Conserv. Biol. 22, 952-964. doi: 10.1111/j.1523-1739.2008.00938.x

Forney, K. A., and Barlow, J. (1998). Seasonal patterns in the abundance and distribution of California cetaceans, 1991-1992. Mar. Mammal Sci. 14, 460-489. doi: 10.1111/j.1748-7692.1998.tb00737.x

Friedlander, A. M., and DeMartini, E. E. (2002). Contrasts in density, size, and biomass of reef fishes between the northwestern and the main Hawaiian islands: the effects of fishing down apex predators. Mar. Ecol. Progr. Ser. 230, e264. doi: 10.3354/meps 230253

Fuentes, M. M. P. B., Bell, I., Hagihara, R., Hamann, M., Hazel, J., Huth, A., et al. (2015). Improving in-water estimates of marine turtle abundance by adjusting aerial survey counts for perception and availability biases. J. Exp. Mar. Biol. Ecol. 471, 77-83. doi: 10.1016/j.jembe.2015.05.003

Google (2013). Google Earth Pro 7.1.1.1580 (beta). Mountain View, CA: Google Inc.

Groombridge, B., and Luxmoore, R. A. (1989). The Green Turtle and Hawksbill (Reptilia: Cheloniidae): World Status, Exploitation and Trade. Cambridge, UK: Secretariat of the Convention on International Trade in Engangererd Species of Wild Fauna and Flora.
Guidetti, P., and Micheli, F. (2011). Ancient art serving marine conservation. Front. Ecol. Environ. 9, 374-375. doi: 10.1890/11.WB.019

Hartup, J., Marshell, A., Stevens, G., Kottermair, M., and Carlson, P. (2013). Manta alfredi target multispecies surgeonfish spawning aggregations. Coral Reefs 32, 367-367. doi: 10.1007/s00338-013-1022-4

Hawkes, L. A., Broderick, A. C., Godfrey, M. H., and Godley, B. J. (2009). Climate change and marine turtles. Endang. Species Res. 7, 137-154. doi: 10.3354/esr00198

Hensley, R. A., and Sherwood, T. S. (1993). An overview of Guam's inshore fisheries. Mar. Fisher. Rev. 55, 129-138.

Hill, M. C., Ligon, A. D., Deakos, M. H., A. C. Ü., Milette-Winfree, A., Bendlin, A. R., and Oleson, E. M. (2014). Cetacean Surveys in the Waters of the Southern Mariana Archipelago (February 2010 - April 2014). Prepared for the U.S. Pacific Fleet Environmental Readiness Office. Honolulu, HI: PIFSC Data Report DR-14-013, NOAA Fisheries.

IUCN (2015). The IUCN Red List of Threatened Species. Version 2015.2. Available online at: www.iucnredlist.org. Downloaded on 14 August 2015

Jones, T. T., and Van Houtan, K. S. (2014). Sea Turtle Tagging in the Mariana Islands Range Complex (MIRC). Honolulu, HI: Annual Progress Report to the Navy, NOAA Fisheries.

Jones, T. T., Van Houtan, K. S., Bostrom, B. L., Ostafichuk, P., Mikkelsen, J., Tezcan, E., et al. (2013). Calculating the ecological impacts of animal-borne instruments on aquatic organisms. Methods Ecol. Evol. 4, 1178-1186. doi: 10.1111/2041-210X.12109

Kessel, S., Gruber, S., Gledhill, K., Bond, M., and Perkins, R. (2013). Aerial survey as a tool to estimate abundance and describe distribution of a carcharhinid species, the lemon shark, negaprion brevirostris. J. Mar. Biol. 2013:597383. doi: $10.1155 / 2013 / 597383$

Kittinger, J. N., Van Houtan, K. S., McClenachan, L. E., and Lawrence, A. L. (2013). Using historical data to assess the biogeography of population recovery. Ecography 36, 868-872. doi: 10.1111/j.1600-0587.2013.00245.x

Koh, L. P., and Wich, S. A. (2012). Dawn of drone ecology: low-cost autonomous aerial vehicles for conservation. Trop. Conserv. Sci. 5, 121-132. Available online at: http://tropicalconservationscience.mongabay.com/content/v5/index-jun12.html

Lewison, R. L., Crowder, L. B., Read, A. J., and Freeman, S. A. (2004). Understanding impacts of fisheries bycatch on marine megafauna. Trends Ecol. Evol. 19, 598-604. doi: 10.1016/j.tree.2004.09.004

Lotze, H. K., Coll, M., Magera, A. M., Ward-Paige, C., and Airoldi, L. (2011). Recovery of marine animal populations and ecosystems. Trends Ecol. Evol. 26, 595-605. doi: 10.1016/j.tree.2011.07.008

Magurran, A. E., Baillie, S. R., Buckland, S. T., Dick, J. M., Elston, D. A., Scott, E. M., et al. (2010). Long-term datasets in biodiversity research and monitoring: assessing change in ecological communities through time. Trends Ecol. Evol. 25, 574-582. doi: 10.1016/j.tree.2010.06.016

Marsh, H., and Sinclair, D. F. (1989). Correcting for visibility bias in strip transect aerial surveys of aquatic fauna. J. Wildl. Manag. 53, 1017-1024. doi: $10.2307 / 3809604$

McClenachan, L., (2009a). Documenting loss of large trophy fish from the Florida Keys with historical photographs. Conserv, Biol. 23, 636-643. doi: 10.1111/j.1523-1739.2008.01152.x

McClenachan, L., (2009b). Historical declines of goliath grouper populations in South Florida, USA. Endang. Spec. Res. 7, 175-181. doi: 10.3354/esr00167

McClenachan, L., Cooper, A. B., McKenzie, M. G., and Drew, J. A. (2015). The importance of surprising results and best practices in historical ecology. BioScience 65, 932-939. doi: 10.1093/biosci/biv100

Myers, R. A., and Worm, B. (2003). Rapid worldwide depletion of predatory fish communities. Nature 423, 280-283. doi: 10.1038/nature01610

Nadon, M. O., Baum, J. K., Williams, I. D., McPherson, J. M., Zgliczynski, B. J., Richards, B. L., et al. (2012). Re-Creating Missing Population Baselines for Pacific Reef Sharks Recreación de las Líneas de Base Poblacionales Faltantes para Tiburones de Arrecife en el Pacífico. Conserv. Biol. 26, 493-503. doi: 10.1111/j.1523-1739.2012. 01835.x

Nurse, L., McLean, R., Agard, J., Briguglio, L., Duvat-Magnan, V., Pelesikoti, N., et al. (2014). "Small Islands," in Climate Change 2014: Impacts, Adaptation, and Vulnerability. Part B: Regional Aspects. Contribution of Working Group II to the Fifth Assessment Report of the Intergovernmental Panel on Climate Change, 
eds V. R. Barros, C. B. Field, D. J. Dokken, M. D. Mastrandrea, K. J. Mach, T. E. Bilir, et al. (Cambridge; New York, NY: Cambridge University Press), 1613-1654.

Pandolfi, J. M., Bradbury, R. H., Sala, E., Hughes, T. P., Bjorndal, K. A., Cooke, R. G., et al. (2003). Global trajectories of the long-term decline of coral reef ecosystems. Science 301, 955-958. doi: 10.1126/science.1085706

Pimm, S. L. (1991). The Balance of Nature?: Ecological Issues in the Conservation of Species and Communities. Chicago, IL: University of Chicago Press.

Porter, V., Leberer, T., Gawel, M., Gutierrez, J., Burdick, D., Torres, V., et al. (2005). "The state of the coral reef ecosystems of Guam," in The State of the Coral Reef Ecosystems of the United States and Pacific Freely Associated States, ed J. Waddell (Silver Spring, MD: NOAA/NCCOS Center for Coastal Monitoring and Assessment's Biogeography Team), 442-487. NOAA Technical Memorandum NOS NCCOS 11.

Pritchard, P. C. H. (1995). "Marine turtles of micronesia," in Biology and Conservation of Sea Turtles, ed K. A. Bjorndal (Washington, DC: Smithsonian Institution Press), 263-274.

R Core Team. (2014). R: A Language and Environment for Statistical Computing. Vienna: R Foundation for Statistical Computing.

Robbins, W. D., Hisano, M., Connolly, S. R., and Choat, J. H. (2006). Ongoing collapse of coral-reef shark populations. Curr. Biol. 16, 2314-2319. doi: 10.1016/j.cub.2006.09.044

Sáenz-Arroyo, A., Roberts, C. M., Torre, J., Cariño-Olvera, M., and EnríquezAndrade, R. (2005). Rapidly shifting environmental baselines among fishers of the Gulf of California. Proc. R. Soc. Lond. B Biol. Sci. 272, 1957-1962. doi: 10.1098/rspb.2005.3175

Sandin, S. A., Smith, J. E., Demartini, E. E., Dinsdale, E. A., Donner, S. D., Friedlander, A. M., et al. (2008). Baselines and degradation of coral reefs in the Northern Line Islands. PLoS ONE 3:e1548. doi: 10.1371/journal.pone.0001548

Scott, R., Hodgson, D. J., Witt, M. J., Coyne, M. S., Adnyana, W., Blumenthal, J. M., et al. (2012). Global analysis of satellite tracking data shows that adult green turtles are significantly aggregated in Marine Protected Areas. Glob. Ecol. Biogeogr. 21, 1053-1061. doi: 10.1111/j.1466-8238.2011.00757.x

Seminoff, J. A., Allen, C. D., Balazs, G. H., Dutton, P. H., Eguchi, T., Haas, H. L., et al. (2015). Status Review of the Green Turtle (Chelonia mydas) Under the U.S. Endangered Species Act. La Jolla, CA: NOAA Technical Memorandum, NOAA-NMFS-SWFSC-539.

Seminoff, J. A., Eguchi, T., Carretta, J., Allen, C. D., Prosperi, D., Rangel, R., et al. (2014). Loggerhead sea turtle abundance at a foraging hotspot in the eastern Pacific Ocean: implications for at-sea conservation. Endang. Spec. Res. 24, 207-220. doi: 10.3354/esr00601

Solow, A. R., Bjorndal, K. A., and Bolten, A. B. (2002). Annual variation in nesting numbers of marine turtles: the effect of sea surface temperature on re-migration intervals. Ecol. Lett. 5, 742-746. doi: 10.1046/j.14610248.2002.00374.x

Thurstan, R. H., McClenachan, L., Crowder, L. B., Drew, J. A., Kittinger, J. N., Levin, P. S., et al. (2015). Filling historical data gaps to foster solutions in marine conservation. Ocean Coast. Manag. 115, 31-40. doi: 10.1016/j.ocecoaman.2015.04.019
Troëng, S., and Rankin, E. (2005). Long-term conservation efforts contribute to positive green turtle Chelonia mydas nesting trend at Tortuguero, Costa Rica. Biol. Conserv. 121, 111-116. doi: 10.1016/j.biocon.2004.04.014

Tupper, M. H. (2007). Spillover of commercially valuable reef fishes from marine protected areas in Guam, Micronesia. Fish. Bull. 105, 527-537. Available online at: http://fishbull.noaa.gov/1054/tupper.pdf

U.S. Census Bureau (2010). 2010 Census Island Areas: Guam. Available online at: https://www.census.gov/2010census/news/press-kits/island-areas/ island-areas.html

van Beukering, P., Haider, W., Longland, M., Cesar, H., Sablan, J., Shjegstad, S., et al. (2007). The Economic Value of Guam's Coral Reefs. Mangilao: University of Guam Marine Laboratory.

Van Houtan, K. S., and Halley, J. M. (2011). Long-term climate forcing in loggerhead sea turtle nesting. PLoS ONE 6:e19043. doi: 10.1371/journal.pone.0019043

Van Houtan, K. S., and Kittinger, J. N. (2014). Historical commercial exploitation and the current status of Hawaiian green turtles. Biol. Conserv. 170, 20-27. doi: 10.1016/j.biocon.2013.11.011

Van Houtan, K. S., Kittinger, J. N., Lawrence, A. L., Yoshinaga, C., Born, V. R., and Fox, A. (2012). Hawksbill sea turtles in the northwestern Hawaiian Islands. Chelonian Conserv. Biol. 11, 117-121. doi: 10.2744/CCB-0984.1

Van Houtan, K. S., McClenachan, L., and Kittinger, J. N. (2013). Seafood menus reflect long-term ocean changes. Front. Ecol. Environ. 11, 289-290. doi: 10.1890/13.WB.015

Ward-Paige, C. A., Mora, C., Lotze, H. K., Pattengill-Semmens, C., McClenachan, L., Arias-Castro, E., et al. (2010). Large-scale absence of sharks on reefs in the Greater-Caribbean: a footprint of human pressures. PLOS ONE 5:e11968. doi: 10.1371/journal.pone.0011968

Wiles, G. J., Aguon, C. F., Davis, G., and Grout, D. (1995). The status and distribution of endangered animals and plants in northern Guam. Micronesica 28, 31-49.

Williams, I. D., Richards, B. L., Sandin, S. A., Baum, J. K., Schroeder, R. E., Nadon, M. O., et al. (2011). Differences in reef fish assemblages between populated and remote reefs spanning multiple archipelagos across the central and western Pacific. J. Mar. Biol. 2011:826234. doi: 10.1155/2011/826234

Willis, K. J., and Birks, H. J. B. (2006). What is natural? The need for a longterm perspective in biodiversity conservation. Science 314, 1261-1265. doi: $10.1126 /$ science. 1122667

Conflict of Interest Statement: The authors declare that the research was conducted in the absence of any commercial or financial relationships that could be construed as a potential conflict of interest.

Copyright (c) 2016 Martin, Van Houtan, Jones, Aguon, Gutierrez, Tibbatts, Wusstig and Bass. This is an open-access article distributed under the terms of the Creative Commons Attribution License (CC BY). The use, distribution or reproduction in other forums is permitted, provided the original author(s) or licensor are credited and that the original publication in this journal is cited, in accordance with accepted academic practice. No use, distribution or reproduction is permitted which does not comply with these terms. 